\title{
Development of the Views about Nature of Engineering Knowledge Questionnaire (Other)
}

Allison Antink-Meyer, Illinois State University

Allison Antink-Meyer is a pre-college science and engineering educator at Illinois State University.

Dr. Ryan A Brown, Illinois State University

Ryan A. Brown is a Professor in Secondary Education at Illinois State University 
Development of the Views about Nature of Engineering Knowledge (VNOEK) Questionnaire

\section{Introduction}

The inclusion of engineering learning standards in most US states, often via their inclusion in state science standards [12], has increased the demand for engineering professional development (PD) for K-12 teachers. Gaps in teachers' understanding about engineering can contribute negatively to students' understanding because teacher's adoption, adaptation, and creation of instruction are influenced by their epistemological views [17]. As engineering education continues to gain attention in K-12 settings, gaps in teachers' understandings about engineering and engineering education, specifically among K-8 teachers and high school science teachers, and engineering edution, sp [0] [11] [15] These are likely resultant from the lack of engineering have emerged [2] [4] [5] [6] [8] [11] [15]. These are likely resultant from the lack of engineering having coursework or other experiences related to engineering [3].

Whether PD is effective must be determined by evidence of its impact on participants. Our ability to evaluate $\mathrm{PD}$ that promotes specific understandings about the nature of engineering ability to evaluate $P D$ that promotes specific understandings about the nature of engineen knowledge (NOEK) is limited by the lack of an adequate instrument, a problem that we attempted to address in this study. This is a validation study of an open-ended questionnaire, the Views about the Nature of Engineering Knowledge (VNOEK) Questionnaire, which was designed to gather K-16 teachers' views about the NOEK. The questionnaire was created as par of our work providing engineering professional development (PD) and coursework to K-12 teachers. Other questionnaires (VNOE, multiple forms Deniz et al., 2016), surveys, and tools (e.g. Draw an Engineer task [10]) exist and these have been used to understand how teachers view engineering and engineering knowledge in various ways [9] [18]. We wished to make inferences about teachers' understanding of the epistemology of engineering and engineering design through engineering-specific scenarios. Existing tools did not satisfy these specific constraints, so we used a previously published framework of the NOEK [1] to guide the development of a new questionnaire.

This ASEE paper will a) summarize the NOEK framework used to frame the VNOEK; b describe the development of the VNOEK questionnaire; (c) discuss the validity and reliability of the VNOEK; (d) describe the participant groups in the validation study; and (e) discuss the use of the VNOEK for work with K-16 teachers.

\section{Evaluating Teachers' Views about the Nature of Engineering Knowledge}

The questionnaire we developed is not the first instrument of its kind. Existing instruments, including the Views of the Nature of Engineering (VNOE) questionnaire [9] and the Pleasants and Olson [14] Nature of Engineering tool for use with elementary teachers, are also available. The VNOE was first and is designed to evaluate teachers' conceptions about engineering within five areas: demarcation, engineering design process, tentativeness, creativity, and socio-culthin ember ember VNOE wh, and he but aspects of enged for use becuse there were addition fean, the first features of the nature of engineering knowledge that we were promoting in our work with teachers. We needed an instrument that would elicit views aligned with our focus.

The conceptual framework, the NOEK framework, used in our work with teachers guided the design of this new questionnaire [1]. The framework consists of seven features of engineering knowledge and design that are co-dependent with one another. These features are categorized as descriptions of engineering knowledge which is:

- interdisciplinary, it affects other knowledge domains like science and is also affected by them;

- contextually responsive, it balances criteria and constraints and changes over time;

- empirical, the optimization process is characteristic of engineering which is evidencebased, and modelling is the central means of data gathering and feedback,

- solution oriented, it is motivated by human problems and desires for new and improved systems, processes, and artifacts,

- personal, engineers generate unique solutions and processes to identical problems because they have individual perspectives, experiences, and insights,

- societally and culturally relevant, it is affected by, and also effects, societies, cultures, communities and geographies, and

- social, it is often team-based and develops based on peer, colleague, and client feedback.

Elements of this framework reflect other NOE descriptions in the literature [9] [14] and it is also supportive of those other articulations. However, it is not identical, and we needed an instrument that would reflect the descriptions of the features in ways more specific than the existing questionnaires would. Our purpose was to design and validate an open-ended NOEK questionnaire aligned with the framework selected in order to further understanding about how teachers view the epistemology of engineering. The literature around teachers' understanding growing, but effective teacher education strategies have not been established. Supporting this growing, but cflectis engineering how they come to know it and ultimately, how it impacts their students. We view his instruments, the creation of which was the purpose of this work.

\section{Development of the Views about Nature of Engineering Knowledge (VNOEK)
Questionnaire}

The VNOEK was designed to be holistically evaluated and categorical ratings (referred to as scores) are generated for each of the seven features of the NOEK; similar to the well-established Views of Nature of Science (VNOS) and Views about Scientific Inquiry (VASI) questionnaires. Therefore, questionnaire items elicit views about each of the seven features, which are the focus of scoring. The open-ended nature of each item was understood to precipitate views relevant to multiple NOEK features. We first describe the design of the items followed by descriptions of the design of the scoring procedures. However, this work was not conducted in isolated stages, but instead the questions and evaluation procedures were developed in tandem. 
We first generated open-ended questions aligned to each feature of the NOEK framework and created a grid consisting of each question, every feature we believed the question might elicit views about, and a description of the features. These questions were created by both authors based on engineering scenarios that were believed to be accessible to a population with limited engineering training. Both authors had engineering training and engineering education expertise, the first author also had career experience in engineering. The questions were designed to be authentic enough that engineers with expert knowledge relevant to the scenarios may have space to reflect on their, potentially, more nuanced understanding. Item feedback was first gathered from two nature of science (NOS) evaluation experts because the process of questionnaire development could be informed by their experiences. Initial revisions were made to the structure of the questions based on their feedback. Specifically, question length, organization and wording revisions were made. Next, the revised items were used to gather feedback from four NOE experts. This resulted in further revisions to the engineering scenarios and to question wording.

The updated items were placed in the grid and realigned with the NOEK feature names and descriptions. Meetings between the authors and NOE experts were conducted in which they were they believed the questions aligned to. Content validity was established through this process they believed the questions aligned to. Content validity was established through this process clarity, and comprehensiveness. During this time the evaluation procedures for the questionnaire were also emerging. While some existing questionnaires that evaluate NOS and NOE use three were also emerging. While some existing questionnaires that evaluate NOS and NOE use three categories (e.g. naive, transitional/mixed, informed) to describe the extent of alignment with descriptions of epistemological aspects, we wanted to develop a classification system of views that would specifically distinguish between problematic conceptions, emergent views, genera understanding, and expertise. The purpose of this was to allow the questionnaires to inform specific modifications to PD and to better inform the evaluation of PD efficacy. Table 1 summarizes the final grid resultant from the content validity procedures. Item numbers are shown at the top and correspond to the questions that follow, and the NOEK features are along the left side of the table.

Table 1. VNOEK Item and NOEK features correspondence

\begin{tabular}{|c|c|c|c|c|c|c|c|c|c|c|c|c|c|}
\hline & 1 & 2 & 3 & 4 & 5 & 6 & 7 & 8 & 9 & 10 & 11 & 12 & 13 \\
\hline $\begin{array}{l}\text { Contextually responsive: balance of criteria and } \\
\text { constraints; evolutions of design and design } \\
\text { processes }\end{array}$ & $\mathrm{X}$ & $\mathrm{x}$ & $\mathrm{X}$ & & $\mathrm{x}$ & & & & & & & & \\
\hline $\begin{array}{l}\text { Empirical: optimization is a central process; } \\
\text { design is evidence based; modeling is the central } \\
\text { means of data gathering and feedback }\end{array}$ & & $x$ & & & & & & & & & $\mathrm{X}$ & $\mathrm{x}$ & \\
\hline $\begin{array}{l}\text { Solution-oriented: motivated by human problems } \\
\text { and desires for new and improved systems, } \\
\text { processes, and artifacts }\end{array}$ & & & $\mathrm{X}$ & $\mathrm{X}$ & $\mathrm{X}$ & $\mathrm{x}$ & & & & & & & \\
\hline $\begin{array}{l}\text { Personal/Individual: reflective of the personal, } \\
\text { professional, and academic experiences; } \\
\text { individuals can generate unique solutions to } \\
\text { identical problems }\end{array}$ & & & & & & & $\mathrm{x}$ & $\mathrm{X}$ & & & & & \\
\hline
\end{tabular}

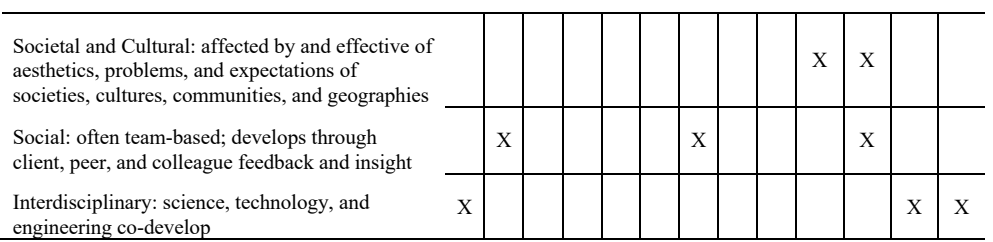

\section{Final VNOEK Questionnaire Items}

1) A small community has a water filtration system that was designed 50 years ago. A group of individuals volunteer to propose a new design for the system. Identify the types of information the volunteers will need in order to propose a new design.

3) Do you think that their work and ideas will be different than the original designers, 50 years ago? Why or why not?

5) Two different groups of engineers are working at two different companies: Eager Engineers Inc., and Acme Engineering. One group, Eager Engineers Inc., is working on a project to design a type of material similar to concrete that will be able to harden under water. The goal of the project is to create a material that will start out as thick liquid but that will be able to harden in order to anchor bridges and stabilize pipes. Do you consider this pour the concrete-type material into the location where it is needed under water. Do you consider this engineering? pour the concrete-ty
Why or why not?

Do you think that the design process for the Acme Engineering project and the Eager Engineers project will be identical? Explain your answer and provide an example if you can.

Eager Engineers and Acme Engineers are working togehter to design a new bridge structure that will connect two roads on either side of a lake. There are 2 engineers from each company working on the bridge design; 4 engineer Do pou think that tho coll The

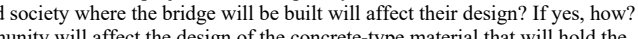
bridge in place? Why or why not?

0) Do you think that the community and es, how? If not, why not? Do you think the community will be affected by the design of the concrete-type material that will hold the bridge in place? Why or why not?

Wear will they decide which idea to use? Explain your answer.

2) What is an engineering model? What is the purpose of an engineering model? What information is used in order 13) create an engineering model?

\section{Pilot with an Intervention Group}

The resulting questionnaire was composed of 13, open ended items where each of the seven features of the NOEK framework would be evaluated against five possible scoring categories. These categories are shown in Table 2 .

Table 2. Rating categories used for each NOEK feature on the VNOEK

\begin{tabular}{lccccc}
\hline Category & Informed (5) & $\begin{array}{c}\text { General (4) } \\
\text { Understanding }\end{array}$ & Emergent (3) & Problematic (2) & Absent (1) \\
\hline $\begin{array}{l}\text { Description of } \\
\text { Category }\end{array}$ & $\begin{array}{c}\text { Desired NOEK } \\
\text { understanding }\end{array}$ & $\begin{array}{c}\text { Missing some of } \\
\text { the definition } \\
\text { but no }\end{array}$ & $\begin{array}{c}\text { Missing most of } \\
\text { the definition } \\
\text { but no }\end{array}$ & $\begin{array}{c}\text { Partial } \\
\text { knowledge } \\
\text { about the aspect }\end{array}$ & $\begin{array}{c}\text { Does not } \\
\text { contain any } \\
\text { NOEK }\end{array}$ \\
\hline
\end{tabular}




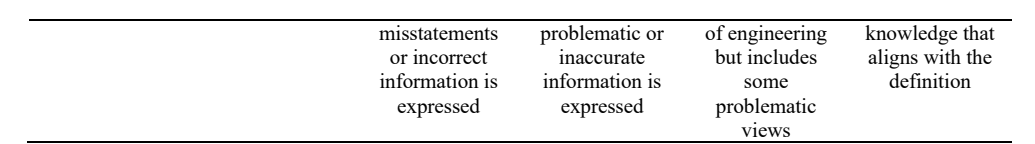

A class of 25 pre-service, middle grades science teachers was used to pilot the VNOEK first. The students had engaged in explicit NOEK instruction and reflection throughout a three-week students had engaged in explicit NOEK instruction and reflection throughout a three-week
module at the end of a 16 -week semester in a science methods course and did not have any previous NOEK or engineering learning experiences. Their responses were used to make final, previous NOEK or engineering learning experiences. Their responses were used to make final, finalized questions and procedures were then used in our validation study. Three scorers evaluated each item for evidence of alignment between specific elements (sub-features) of the descriptions of each NOEK feature in participant responses. The separation of sub-features was descriptions of each NOEK feature in participant responses. The separation of sub-features was
accomplished by taking the descriptions and parsing out individually scorable components. For example, the description of the contextually responsive feature is described in Table 1 as the example, the description of the contextually responsive feature is described in Table 1 as the
balance of criteria and constraints and the evolution of design and design processes. Because this balance of criteria and constraints and the evolution of design and design processes. Because this definition is multifaceted, scoring each element of the description simultaneously was difficult.
Figure 1 illustrates how the description was broken down so that the three scorers could first capture each of the layers of the feature and could use them to derive a single score for the contextually responsive category.

\begin{tabular}{|llll|}
\hline $\begin{array}{l}\text { Subfeature: } \\
\text { criteria } \\
\text { matter }\end{array}$ & $\begin{array}{l}\text { Subfeature: } \\
\text { constraints } \\
\text { matter }\end{array}$ & $\begin{array}{l}\text { Subfeature: engineering } \\
\text { design often changes } \\
\text { over time }\end{array}$ & $\begin{array}{l}\text { Feature: Contextually responsive: balance of criteria } \\
\text { and constraints; evolutions of design and design } \\
\text { processes }\end{array}$ \\
\hline
\end{tabular}

Figure 1. Example of feature and corresponding sub-features from scoring procedure

Each sub-feature was given a rating of yes, no, or somewhat in order to indicate whether evidence of participant understanding of that sub-feature was present, absent, or partial but incomplete. These ratings were then used to inform a decision on a feature score according to the descriptions in Table 2 . An example based on figure 1, the contextually responsive feature, is provided in figure 2. This example comes from the responses of a teacher who identifies their role as a grades 3-4 elementary teacher. Their overall view of engineering is expressed their

community should be considered engineering.

I believe that their work is engineering for several reasons. Firstly, having access to clean water is an example of a human problem. Secondly, the volunteers are working to design a system that solves that problem. Their goal is not to observe and provide an answer to how a filtration system works. Rather, they are using that knowledge to help them design a better solution.

Their response is indicative of a typical response among participants, and this is why they were chosen as an exemplar. Only their responses and ratings on one feature, contextual responsiveness, are illustrated in figure 2 .

\begin{tabular}{|c|c|c|}
\hline $\begin{array}{l}\text { Sub-features } \\
\text { (italics) } \\
\text { Feature: } \\
\text { Contextual } \\
\text { Responsiveness }\end{array}$ & Responses used to inform rating & Rating/Score \\
\hline criteria matter & $\begin{array}{l}\text { "The volunteers will need to know a lot of information to design } \\
\text { an effective filtration system. Some examples include: - The } \\
\text { number of poople in the community that the filtration system will } \\
\text { serve - Knowledge of how/why the old filtration system stopped } \\
\text { working - Where the water source that will go through the } \\
\text { filtration system originates -Scientific knowledge on how a water } \\
\text { filtration system cleans water " }\end{array}$ & $\begin{array}{l}\text { Yes (sufficient } \\
\text { evidence of } \\
\text { understanding role } \\
\text { of criteria in } \\
\text { engineering) }\end{array}$ \\
\hline $\begin{array}{l}\text { constraints } \\
\text { matter }\end{array}$ & $\begin{array}{l}\text { "The volunteers will need to know a lot of information to design } \\
\text { an effective filtration system...Knowledge of cost-effective and } \\
\text { efficient materials for designing the system is needed" }\end{array}$ & $\begin{array}{l}\text { Yes (sufficient } \\
\text { evidence of } \\
\text { understanding role } \\
\text { of constraints in } \\
\text { engineering) }\end{array}$ \\
\hline $\begin{array}{l}\text { engineering } \\
\text { design often } \\
\text { changes over } \\
\text { time }\end{array}$ & $\begin{array}{l}\text { "I think that the new design will most definitely include new } \\
\text { ideas. Scientific knowledge changes over time. Scientists and } \\
\text { engineers have worked together for } 50 \text { years to create water } \\
\text { filtration systems that work better. The volunteers will be able to } \\
\text { access this new knowledge to design an improved system." }\end{array}$ & $\begin{array}{l}\text { Yes (sufficient } \\
\text { evidence of } \\
\text { understanding } \\
\text { engineering design } \\
\text { develops over } \\
\text { time) }\end{array}$ \\
\hline $\begin{array}{l}\text { Contextually } \\
\text { responsive }\end{array}$ & $\begin{array}{l}\text { This is a cumulative rating informed by the three sub-feature } \\
\text { ratings above }\end{array}$ & $\begin{array}{l}\text { Informed (5) } \\
\text { Understanding } \\
\text { aligned with } \\
\text { NOEK framework }\end{array}$ \\
\hline
\end{tabular}

\section{Results: Administration and scoring validation}

Participants in the questionnaire validation study were recruited from two listservs, based in the U.S., for grades K-16 science teachers and grades K-16 technology and engineering teachers. An announcement was posted to each listserv describing the purposes of the validation study and seeking volunteers to complete the questionnaire. Additionally, participants were asked if they would be willing to participate in an interview about their responses at the end of the questionnaire. Respondents that indicated they were willing to participate in an interview were by the first author using a short protocol, and participants were asked to elaborate on any responses that were less clear or more nuanced. They were also asked to comment on the clarity responses that were less clear or more nuanced. They were also asked to comment on the clarity of the items. Interviews contributed to finalizing the scoring procedures because they illuminated
whether a rating was appropriate.

This study was approved by an institutional review board for human subjects research. Tables 3 , 4 , and 5 describe three characteristics of respondents: their professional roles, the extent of 
engineering education they had received, and the extent of professional experiences in engineering.

Table 3. Frequencies of participant roles $(\mathrm{n}=148)$

\begin{tabular}{|c|c|c|}
\hline $\begin{array}{l}\text { Select the role(s) that best } \\
\text { describes you. }\end{array}$ & Frequency & Percent \\
\hline Other & 2 & 1.351 \\
\hline Pre-service teacher & 28 & 18.919 \\
\hline Pre-K-2nd & 11 & 7.432 \\
\hline $3-5$ th & 50 & 33.784 \\
\hline Middle grades & 21 & 14.189 \\
\hline High school & 9 & 6.081 \\
\hline College instructor & 12 & 8.108 \\
\hline $\begin{array}{l}\text { Graduate student in STEM } \\
\text { Education }\end{array}$ & 6 & 4.054 \\
\hline $\begin{array}{l}\text { Graduate student in STEM } \\
\text { discipline }\end{array}$ & 2 & 1.351 \\
\hline Engineer & 7 & 4.730 \\
\hline \multicolumn{3}{|c|}{ Table 4. Frequencies of engineering education $(n=148)$} \\
\hline $\begin{array}{l}\text { Have you received any } \\
\text { engineering education? }\end{array}$ & Frequency & Percent \\
\hline None at all $(0)$ & 50 & 33.784 \\
\hline A little (1) & 69 & 46.622 \\
\hline A moderate amount (2) & 11 & 7.432 \\
\hline A lot (3) & 9 & 6.081 \\
\hline A great deal (4) & 9 & 6.081 \\
\hline \multicolumn{3}{|c|}{ Table 5. Frequencies of engineering related work experiences $(\mathrm{n}=148)$} \\
\hline $\begin{array}{l}\text { Do you have any } \\
\text { engineering related work } \\
\text { experiences? }\end{array}$ & Frequency & Percent \\
\hline None at all & 99 & 66.892 \\
\hline A little & 26 & 17.568 \\
\hline A moderate amount & 11 & 7.432 \\
\hline A lot & 5 & 3.378 \\
\hline A great deal & 7 & 4.730 \\
\hline
\end{tabular}

A great deal

Reliability

Two forms of reliability were established; inter-rater reliability and internal consistency. Interrater was established as a percent of agreement between scorers where a value above $70 \%$ is generally acceptable [16]. Using the procedures established during the pilot, at least two people scored every questionnaire. Twenty percent $(\mathrm{n}=29)$ of the questionnaires were then randomly selected and different scorers' evaluations of each feature were compared. The percent agreement between them was $87 \%$; above the accepted value of $70 \%$. For the purpose of this validation study, all inconsistencies in scores were discussed until $100 \%$ agreement was achieved.

Cronbach alpha, the statistic used to describe the internal consistency of the VNOEK, was 0.82 . In addition, we examined what the alpha value would be if any features or sub-features were removed from the scoring procedures and no change in internal consistency was observed above 0.84. This supports the claim that each feature and sub-feature contributes uniformly.

Exploratory Factor Analysis

No gold standard exists with regard to the evaluation of NOEK understanding, therefore this study sought to establish construct validity for the extent that VNOEK results were consistent with the theoretical underpinnings of the NOEK framework. The scoring procedure consisted of sub-scores on sub-features that were then used to inform a score for the NOEK features (see table 2 and figure 1 for illustration). Exploratory factor anasis (EFA) was used with princip components analysis ( $\mathrm{PCA}$ ) and the varimax orthogonal rotation method to determine wheipal these scores loaded onto latent factors together. Although we wished to find that the featues cose sub-featus were cortent hir re .

Initial analyses resulted in the removal of three sub-features from the scoring procedure. Each of them had posed challenges to scoring and had been previously discussed during the inter-rater reliability portion of the study. The EFA confirmed their problematic nature and they were thus removed. Table 6 shows the final results of this analysis after their removal. All loadings were above the recommended value of 0.400 [13]

\section{Table 6. Factor loadings}

Contextually responsive

constraints matter

criteria matter

engineering design often changes over tim

Empirical

engineering design is evidence based

models take a variety of forms and are of central importance Interdisciplinary

engineering impacts science and or technolog science and technology impacts engineerin

' individual backgrounds enerate unique ideas

ocial

ngineering groups influence desig

takeholders (clients) influence design Societal and Cultural

gineering affects its socio-cultura

engineering is affected by its socio-cultural setting

\begin{tabular}{|c|c|c|c|c|c|}
\hline 2 & 3 & 4 & 5 & 6 & 7 \\
\hline .0 .926 & & & . & & \\
\hline 0.723 & . & . & & & \\
\hline 0.701 & . & . & & & \\
\hline 0.608 & & & & & \\
\hline & & & 9.915 & & \\
\hline & . & & .460 & & \\
\hline & & & .884 & & \\
\hline & & . & & 0.961 & \\
\hline & & . & & 0.800 & \\
\hline & & & & 0.620 & \\
\hline & 0.955 & . & & & \\
\hline & 0.827 & . & & & \\
\hline & 0.634 & & & & \\
\hline & & & & & 0.88 \\
\hline & . & . & & & 0.4 \\
\hline & & & & & 0.7 \\
\hline & & 1.931 & & & \\
\hline & & & & & \\
\hline
\end{tabular}


Solution-oriented

engineering creates both new and improved design

engineering solutions can be artifacts

engineering solutions can be processes

engineering solutions can be systen

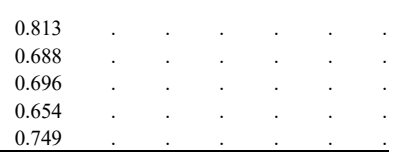

\section{Discussion}

The EFA analysis supports the claim that the seven NOEK factors and their associated subfactors in the VNOEK scoring procedures are measured by the instrument as intended. The PCA

extracted seven factors, and the features and associated sub-features loaded onto those factors identically to their groupings in the framework and scoring procedure. This supports the construct validity of the questionnaire as an instrument that evaluates the specific NOEK features in the framework used. Furthermore, the content validity of the VNOEK was established by the panel of experts and the iterative revision process. The member checking process conducted using interviews with 20 percent of the respondents further supports content validity. Both interrater reliability and internal consistency were also acceptable.

The value of this instrument rests in its sensitivity to layers of understanding relevant within the NOEK features. Intended for teachers, this instrument provides more nuanced information about aspects of teachers' views about the NOEK that can be used to inform teacher supports. Every feature is evalot by between two and four sub-fetures and their alysis suppots the holistic evaluation.

\section{Future Directions}

The validation process for this instrument also reflected part of the utility of EFA as a means to improve a tool [7]. Several, more problematic sub-features emerged and were removed. This improved the instrument and its usability for researchers and PD evaluators. The potential for additional future revisions or other versions are potential future directions for this tool. Although the VNOEK is intended for use with populations of individuals who identify as teachers, its potential for use with students is evident. Future work with undergraduate and graduate science and or engineering majors as well as with high school students is also an area of need. Additiona revisions may be necessary for work with different populations of learners. Some differences between different groups of respondents emerged based on their professional roles and the extent of their engineering education experiences. We do not make claims at this time as to discriminan validity, but initial analyses suggest that the instrument can likely detect differences between individuals who have NOEK training and those who do not. This is an area of future work as is the use of confirmatory factor analysis.

\section{Conclusions}

The gaps in teachers' understanding about engineering that are reported in the literature center mainly around engineering process knowledge as well as around the practices of engineering design [8] [15]. While gaps in understanding in about engineering processes are important (and are in addition to the need for support around pedagogical and pedagogical content knowledge (PCK) for engineering instruction), this project focused on the epistemology of engineering. The teachers targeted by our PD efforts have significantly more training for science education and, anecdotally, we have observed that imbues a science-oriented lens whereby the distinctions and inter-dependencies between science and engineering become conflated. Such conflation is likely insufficiently addressed when PD focused exclusively on engineering processes. Instead, introducing both process knowledge and experience while also promoting reflection on the epistemological nature of engineering knowledge, may provide support for understanding the structure of knowledge about engineering needed by K-12 teachers. This instrument will support inquiry in this area.

\section{References}

1] Antink-Meyer, A., \& Brown, R. A. (2019). Nature of Engineering Knowledge. Science \& Education, 28(3-5), 539-559.

2] Antink-Meyer, A., \& Meyer, D. Z. (2016). Science teachers' misconceptions in science and engineering distinctions: Refl,

[3] Banilower, E. R., Smith, P. S., Malzahn, K. A., Plumley, C. L., Gordon, E. M., \& Hayes, M. L. (2018). Report of the 2018 NSSME+.

[4] Dare, E. A., Ellis, J. A., \& Roehrig, G. H. (2014). Driven by beliefs: Understanding challenges physical science teachers face when integrating engineering and physics. Journal of Pre-College Engineering Education
Research (J-PEER), 4(2), 5.

[5] Duncan, D., Diefes-dux, H., \& Gentry, M. (2011). Professional development through engineering academies: An examination of elementary teachers' recognition and understanding of engineering. Journal of Engineering Education, 100(3), 520-539.

[6] Guzey, S. S., Tank, K., Wang, H. H., Roehrig, G., \& Moore, T. (2014). A high-quality professiona development for teachers of grades 3-6 for implementing engineering into classrooms. School science an

[7] Huck, S. W. (2012). Reading statistics and research.

[8] Hynes, M. M. (2012). Middle-school teachers' understanding and teaching of the engineering design process: A look at subject matter and pedagogical content knowledge. International journal of technology and design education, 22(3), 345-36

[9] Kaya, E., Newley, A., Deniz, H., Yesilyurt, E., \& Newley, P. (2017). Introducing Engineering Design to Science Teaching Methods Course Through Educational Robotics and Exploring Changes in Views of
Preservice Elementary Ters

10] Knight, M., \& Cunningham, C. (2004, June). Draw an engineer test (DAET): Development of a tool to investigate students' ideas about engineers and engineering. In ASEE Annual Conference and Exposition (Vol.

[11] Mesutoglu, C., \& Baran, E. (2020). Examining the Development of Middle School Science Teachers' Understanding of Engineering Design Process. International Journal of Science and Mathematics Education, 112] Moore, T. J., Tank, K. M., Glancy, A. W., \& Kersten, J. A. (2015). NGSS and the landscape of engineering in
K-12 state science standards. Journal of Research in Science Teaching, 52(3), 296-318.

[13] Osborne, J. W., Costello, A. B., \& Kellow, J. T. (2008). Best practices in exploratory factor analysis. Best practices in quantitative methods, $86-99$ 

[14] Pleasants, J. \& Olson, J.K. (2019) "Refining an Instrument and Studying Elementary Teachers' Understanding
of the Scope of Engineering," Journal of Pre-College Engineering Education Research (J-PEER): $9(2)$.

[15] Pleasants, J., Olson, J. K., \& De La Cruz, I. (2020). Accuracy of Elementary Teachers' Representations of the Projects and Processes of Engineering: Results of a Professional Development Program. Journal of Science Teacher Education, 1-22.

[16] Stemler, S. E. (2004). A comparison of consensus, consistency, and measurement approaches to estimating interrater reliability. Practical Assessment, Research \& Evaluation, 9

[17] Tsai, C. C. (2007). Teachers' scientific epistemological views: The coherence with instruction and students' views. Science Education, 91(2), 222-243.

[18] Vazquez, A., \& Marti, M. E. J. Cross-Cultural Training and Engineering: An Illustration Using Vietnamese Engineering Faculties' Responses to Nature of Engineering Instrument (Work in Progress). ASEE 